\title{
Sustainable Supply Chain Management Practices and Operational Performance
}

\author{
Maruf Hasan \\ School of Mechanical \& Manufacturing Engineering, The University of New South Wales, Sydney, Austalia. \\ Email:m.hasan@unsw.edu.au
}

Received September $21^{\text {st }}$, 2012; revised October $23^{\text {rd }}, 2012$; accepted November $25^{\text {th }}, 2012$

\begin{abstract}
Sustainable supply chain management has emerged as a key approach for enterprises aiming to become environmentally sustainable. The study will investigate the kinds of environmental management practices that are undertaken by companies in greening the supply chain and how these practices affect the environmental and operational performance of the companies. The study provides additional insight into the growing field of literature examining the relationships between environmental policies and operational performance.
\end{abstract}

Keywords: Management; Supply Chain; Environment; Performance

\section{Introduction}

Environmentally conscious business practices have been receiving increasing attention from both researchers and practitioners. The number of organisations contemplating the integration of environmental practices into their strategic plans and operations is continuously increasing [1]. Numerous initiatives have provided incentives for organizations to become more environmentally friendly. The concepts pertaining to supply chain environmental management (SCEM) or greening the supply chain are usually understood by industry as screening suppliers for environmental performance and then doing business with only those that meet regulatory standards [2]. The driving forces for introducing and implementing the concept into the company operations are numerous and comprise a range of "reactive regulatory reasons to proactive strategies and competitive advantage reasons" [3]. Approaches such as cleaner production, environmental management systems and eco-efficiency have been implemented for green management practices. The factors driving the competitive advantage through environmental performance have been identified as market expectations, risk management, regulatory compliance and business efficiency [4]. Green supply chain management (GSCM) has a key role in ensuring that all of these factors are addressed [5]. Environmental impact occurs at all stages of a product's life cycle. Therefore GSCM has emerged as an important new archetype for enterprises to achieve profit and market share objective by lowering the environmental risks and impacts and while raising their ecological efficiency [6]. In this paper the terms SCEM and GSCM will be used interchangeably.

\section{Literature Review}

The concept of supply chain management has been observed as a recent and novel tool and the literature in green supply chain management has been growing in recent years. Min and Galle [7] conducted an empirical survey of US purchasing managers with regard to green purchasing and have found that that the primary driving force to green purchasing is an urge to meeting regulations rather than environmental monitoring or partnerships. The effectiveness of green purchasing also depends on whether the firm has centralised or decentralised decision-making [8], which determines the extent of flexibility in the green purchasing process. In a survey, purchasing managers listed the impact of environmental regulations on purchasing activities as their second most important future concern [9].

The relationship between GSCM and organisational performance has been investigated [10] but the results have not been conclusive. There exist two contrasting views about the relationship between environmental practices and organisational performance. The first viewpoint argues that many managers believe that environmental management consists simply of compliance with regulations, and that a trade-off exists where increased level of environmental management results in increased cost [11]. This relationship might exist in part due to increased costs associated with the transference of externalities, such as the cost of polluted air, back to the firm [12]. Gallop and Roberts [13] studied the effects of en- 
vironmental regulations on the cost of operations in the electricity utilities industry and found a similar effectenvironmental regulations were associated with a decline in industry productivity.

There is also a body of research that suggests a positive relationship between environmental practices and organisational performance. Klassen and Mclaughlin's [12] proposed model and empirical findings suggests a positive effect of environmental performance through both market and cost pathways. Recent literature has provided insight on the potential pattern of supply chain practices for improving environmental performance [1416]. The literature for supporting this positive relationship is relatively strong [17]. Frosch [18] argued that an inter-firm linkage facilitated by proximity could lead to an improvement in environmental performance. Geffen and Rothenberg [19] suggested that relations with suppliers aid the adoption and development of innovative environmental technologies. Furthermore, the interaction of customer and supplier staff, partnership agreements and joint R \& D leads to improved environmental performance. It is not very clear whether GSCM practices relate to positive or negative economic performance [20]. Alvarez et al. [21] indicated that environmental management such as GSCM has a positive relationship with an organisation's economic performance. According to Klassen and Mclaughlin [12], organisations that minimise the negative environmental impacts of their products and processes, recycle post-consumer waste and establish environmental management systems are poised to expand their markets or displace competitors that fail to promote strong environmental performance. However, Bowen et al. [22] suggested economic performance is not being reaped in short-term profitability or sales performance. Szwilski [23] indicated that an environmental management system is an innovative environmental policy and information management tool for industry to improve organisational performance. Tooru [24] demonstrated, using a case study, that an environmental management system can improve operational performance of a firm. Hanna et al. [25] observed a strong relationship between the meeting of goals and staff involvement on environmental management.

Revenues can be positively impacted when customers prefer the products of environmentally friendly firms [26], resulting in increased market share vis-a-vis less environmentally oriented competitors. Costs can be lowered when firms invest in environmental management systems that result in a decrease in accidental environmental releases and liability. Costs may be reduced through proactively managing environmental regulations, which may create barriers and first-mover advantages that are difficult for competitors to imitate $[27,28]$. Orlitzky et al. [29] showed, based on a meta-analysis inte- grating 30 years of research, that there is a positive association between corporate social performance and corporate financial performance across industries.

There is a dearth of empirical research concerning GSCM practices and organisational performance and it is important to investigate the effect of green supply chain management practices on environmental and operational performance of organizations.

The aims of the study (research questions) are the following:

1) What kind of environmental management practices are undertaken by organisations in order to improve their environmental performance?

2) How does the practice of green supply chain management practices affect the environmental and operational performance of organisations?

A research framework is developed to investigate the relationships between three SSCM practices that companies may implement to improve their performance. SSCM practice dimensions and items are based on previous literature that addressed various aspects of SSCM [30-33]. The framework is given in Tables $\mathbf{1}$ and $\mathbf{2}$.

A description of the GSCM practices and performance constructs is given below:

There is agreement within the literature that environmental management practices in the organisation are a key to improve enterprise performance [34]. It is well

Table 1. Environmental management practices within the organization.

Environmental management practices within the organization

Commitment of GSCM from senior and middle level managers

Total quality environmental management

Environmental compliance and auditing program

ISO 14000 certification

SSCM practices relating to suppliers and customers

Cooperation with suppliers for environmental objectives

Supplier's ISO14000 certification

Company-wide environmental audits

Environmental management for suppliers internal management

Provide training to build supplier environmental management capacity

Cooperation with customers for eco-design and cleaner production

Cooperation with customers for green packaging

Environmentally conscious product and process design

Environmentally friendly raw material

Design of products for reduced consumption of material and energy Design of products for reuse, recycle, recovery of material, component parts

Design of products to avoid or reduce use of hazardous products and/or their manufacturing process

Optimization of process to reduce solid/liquid waste and emission

Use reverse logistics 
Table 2. Environmental and operational performance constructs.

\begin{tabular}{l}
\hline Environmental performance \\
\hline Reduction of solid/liquid waste and emissions \\
Reduction of consumption for hazardous/toxic materials \\
Reduction of frequency of environmental accidents \\
Reduction of electricity usage \\
\hline Operational performance \\
\hline Cost savings and increased efficiency \\
Product quality improvement \\
Increase in market share \\
New market opportunities \\
Enhance employee motivation and performance \\
Increase in sales
\end{tabular}

known that senior manager's support is necessary, and often a key driver for successful adoption and implementation of most innovations, technology, programs and activities [35]. Reference [34] concluded that support from mid-level managers is also key to successful implementation of GSCM practices. Bowen et al. [22] used middle managers to find positive relationships between middle managers' perceptions of corporate environmental pro-activity and environmental management.

GSCM practices relating to suppliers and customers are concerned with the "inbound" and "outbound" aspects of supply chain management. From the "inbound" perspective of the supply chain it is argued that greening the supply chain has numerous benefits for an organization, ranging from cost reduction, to integrating suppliers in a participative decision making process that promotes environmental innovation [2,22]. A large part of the inbound function essentially comprises of green purchasing strategies adopted by organisations in response to increasing global concerns of environmental sustainability [7]. Walton et al. [36] examine the integration of suppliers into environmental management processes, and observe two evolving trends. They firstly suggest that environmental issues are becoming an intrinsic part of strategic planning in organisations due to stricter regulations and the demands of environmental accountability. They also observe a second trend amongst their case examples, that organisations are integrating their supply chains to reduce operating costs and improve their customer service. Green purchasing strategies arguably resolve around two key components, the evaluation of suppliers' environmental performance and mentoring to assist suppliers to improve their performance. Reference [37] has detailed the range of tools and techniques in place to assess the environmental behaviour of suppliers to aid in supplier selection. Often organisations urge suppliers to develop their own in-house environmental management system, and many request that a supplier accredits to an environmental management standard such as ISO 14001 [38].

On the outbound side of green supply chain, green marketing, green packaging and environmental friendly distribution are all initiatives that might improve the environmental performance of the supply chain [2,3]. Packaging performs a number of functions including containment, protection, preservation, apportionment, unitisation and presentation [32]. In order to address the environmental impact of packaging, many countries now have programs that aim to minimise the amount of packaging that enters the waste stream. The reuse of packageing can be found in reusable, collapsible shipping containers [39]. Green marketing has an important part to play in the link between environmental innovation and competitive advantage [40]. Encouraging suppliers to take back packaging is a form of reverse logistics that can be an important consideration in greening the out-bound function. Reference [41] argued that standardised reusable containers, good merchandising layouts, and easy information access reduce storage and retrieval delays which leads to cost saving whilst being environmentally friendly.

Environmentally conscious product and process design may purposely incorporate a number of concepts such as environmentally friendly raw material, design for reduced consumption of material and energy, use of cleaner technology processes to reduce solid and liquid waste and use of reverse logistics. Investment recovery is an emerging environmental practice and many enterprises have considered investment recovery as a critical aspect for GSCM [30].

\section{Case Studies}

Case study research is used to validate the framework. Convenience sampling was used to select the companies for case studies. Convenience sampling is a non-probability sampling technique where subjects are selected based on their easy accessibility. The necessary information required from the five companies selected were accessible and readily available. All the companies selected have exercised substantial effort in managing supply chain that is sustainable. Case studies were conducted in order to investigate various sustainable supply chain management practices and the environmental and operations results derived out of this. The studies are mostly based on published documents such as reports and publications. A description of the cases is given below:

\subsection{Eastman Chemical Company}

Eastman Chemical Company is focused on continual im- 
provement and value creation in all aspects of the supply chain such as, measuring supplier performance, developing alternative methods of supply, develop supplier solution, improve packaging, use renewable material, design and optimize supply chain network, develop customer solutions and manage investment recovery [42]. Eastman tracks a variety of environmental measures and expanded the environmental performance matrics and included greenhouse gas intensity reduction goal in addition to energy efficiency goal and TRI (Toxic Release Inventory) releases and reportable releases.

Eastman's energy policy has balanced the need for affordable energy supplies with the need to reduce the amount of energy needed to make their products. Eastman's integrated manufacturing process results in very efficient operations, allowing heat from one chemical process to be used for heat within a different chemical process. The water management practices of Eastman are very good in efficient use and pollution prevention. Eastman takes great care to manage on-site waste reduction and recycling. Eastman focuses on renewable materials and packaging to limit the end-of-use waste of the products.

\subsection{Westpac Bank, Australia}

Westpac Bank aims to ensure that suppliers must share their commitment to best practices, continuous improvement and collaborative approaches, deal ethically and responsibly with suppliers and build corporate and long term relationships [43]. Westpac also set a clear and unambiguous minimum standard of supplier behaviour for key business practices, via a sustainable supply chain management (SSCM) code of conduct. SSCM enables Westpac to create other benefits such as reduced costs, improved risk management, enhanced quality and product or service innovation. Westpac also undertakes detailed assessment of high spend and higher risk suppliers to ensure a more in-depth understanding of the social, ethical and environmental business practices of these supplier.

Sustainability is a core component of Westpac Bank's culture and corporate strategy. Part of this is managing their environmental impact and dealing with the critical issue of climate change. Westpac supports emission trading and other market mechanism in order to effect positive environmental outcomes. Westpac is committed to efficient eater management and water conservation. Westpac's supplier selection process included questions regarding the management of environmental issues.

\subsection{New Zealand Business Council for Sustainable Development}

New Zealand Business Council for Sustainable Devel- opment is involved in improving the business's own operations, ensuring that the goods and services provided by suppliers to increase efficiency and competitiveness and working effectively with customers and sales and distribution to design sustainable products and services [44].

A great benefit lies in working with supplier and customers to improve the design of products and processes that connect business with customers. Some success has been achieved in redesigning packaging and in increasing the recyclable content in a variety of products. Process collaboration with suppliers and customers has been shown to deliver improvement in manufacturing and logistics efficiency whilst reducing emissions, road congestion and improving employment stability. One way in which companies can differentiate themselves, reduce cost and improve service is to consider the environmental, social as well as economic factors related to the supply chain.

Dow Jones has valued more than 300 companies in relation to their sustainable development in the Dow Jones Sustainability Group Index (DJSI), the index provides evidence that sustainable development pays, with companies in the index underperforming the Dow Jones Group Index. One of the parameters that can have a negative influence on corporate reputation and share price is whether the company's supply chain is socially responsible and accountable. In relation to risk management, any actions which may be seen as inconsistent with Shell Group Business Principles can potentially lead to damage to the group's reputation and its business. Sanford's business in New Zealand is based on the growth and harvesting of wild fish and shell fish with the sustainable fish quota management system and is entirely dependent upon long-term fish supply. Sanford's prices for 'sustainable Hoki' have increased following accreditations. Consumers are prepared to pay a premium for certified fish.

Companies embracing sustainable development can benefit from being a first mover in a market. All else being equal, $82 \%$ of UK consumers prefer to purchase goods from socially and environmentally responsibly companies, according to a 2003 study, and $23 \%$ would do so even if this option is more expensive.

Driving out inefficiency from processes is good business practice and reduces costs. In the service sector, introducing video conferencing reduces energy consumption and emissions associated with travel' increased productivity and reduces costs.

\subsection{Coca Cola Enterprises}

In 2007 Coca Cola Enterprises set five strategic Corporate Responsibility and Sustainability (CRS) focus areas. These areas are energy conservation/climate change, 
sustainable packaging/recycling, product portfolio/wellbeing, and diverse and inclusive culture [45]. In 2008, Coca Cola made an investment of US \$34.8 million on capital projects in their three environmental focus areas. They are now establishing a cost-benefit analysis process to prioritize CRS investments. Coca Cola Company has set the following goals in the area of energy conservation, water stewardship, sustainable packaging/recycling, product portfolio/well-being and diverse and inclusive culture:

Reduce the overall carbon footprint by 15 percent by 2020, as compared to 2007 baseline. Establish a watersustainable operation in which water use will be minimized and have a water-neutral impact on the local communities in which they operate, by safely returning the amount of water equivalent to what they use in their beverages and their production. Reduce the impact of packaging: maximizing the use of renewable, reusable, and recyclable resources; recover the equivalent of 100 percent of packaging, which creates a culture where diversity is valued, every employee is a respected member of a team, and workforce is a reflection of the communities in which they operate.

In order to reduce overall carbon footprint, Coca Cola measured their carbon footprint, calculated the first certified product carbon footprint of sparkling beverages, and increase hybrid fleet by 120 trucks. To establish a watersustainable operation, the company reduced water use ratio to 1.73 litres, saved 301 million litres of water through efficiency initiatives and launched pilot study of embedded water footprint. To reduce the impact of packaging, Coca Cola avoided use of approximately 31,000 metric tons of packaging materials, or 2.7 percent of total used, recovered and recycled approximately 125,000 metric tons of packaging and reached 90 percent waste recycling at an additional 14 facilities. In the area of product portfolio well-being, the company introduced first zero-calorie sports drink, POWERADE Zero, reduced average calorie content of the portfolio by three percent since 2006 and introduced first naturally sweetened low-calorie beverage.

\subsection{Ernst and Young Survey}

A survey of executives from \$1bn-plus corporation conducted by Ernst \& Young indicates a high level of awareness of sustainability, with an appreciation of the opportunities it offers within supply chain [46].

Reputation, cost reduction and revenue growth were the top three widespread opportunities cited by more than half of respondents. An increase cost base was also highlighted as the greatest risk, suggesting that anticipated operational and energy savings would be offset by increased capital cost and increase price from suppliers. Regulatory compliance was reported as both an opportu- nity and threat, indicating that there will be individual winners and losers, depending on firms' preparedness to stay ahead of new legislation.

There is a strong possibility that carbon will become a parallel currency to money in the future. More business will need to operate within carbon cap, or else pay for the excess carbon produced. Therefore it is important for the international companies to take steps to measure their supply chain emissions in order to predict future cost and liabilities. To combat increasing energy prices and reduce in-house emissions, $40 \%$ of the firms have invested in on-site renewable energy generation. This offers great control over energy cost, enhances corporate reputation and may result in profits from the sale of surplus renewable electricity.

An increasing number of businesses are competing to launch sustainable products and services to increase their market share. $63 \%$ of respondents see sustainability as an opportunity for revenue growth. $71 \%$ view reputation and brand as the area where sustainability, green and carbon issues will provide opportunity. The survey also found that $44 \%$ of the respondents said they are confident they can deal with sustainability issues. Many large global companies have yet to realize the full potential of the savings and benefits due to sustainable supply chain management.

\section{Discussion}

From the case study analysis it is found that the companies studied are involved with suppliers to increase efficiency and working effectively with customers to design sustainable products and services. Most of the companies are involved in measuring supplier performance, developing alternative methods of supply, develop supplier solution and build long term relationship with suppliers. Most of these companies are involved in developing improved packaging, and increasing the recyclable content of the products. Some of these companies have certification to environmental management standards such as ISO14000. Most of the practices cited are in agreement with the framework of SSCM practices dimensions.

In relation to the environmental and operational performance a wide range of opportunities were cited by the companies. Among the key environmental performance measures, greenhouse gas emission reduction, improvement in energy efficiency and conservation of resources logistics efficiency were evident in most of the companies. Other benefits achieved by companies are increased efficiency, reduced cost, improved risk management, improved service, increased sales and market share, revenue growth and reputation. It is important that the company's supply chain is socially responsible and ethical. One of the dimensions in operational performance that needs to be incorporated to the framework is improved risk man- 
agement and reputation.

From the study of these organisations it can be concluded that SSCM practices have considerable effect on the environmental and operation performance of organisations. More in-depth case studies will be conducted in order to further validate/modify the framework. One of the limitations of the study is that the convenience sampling used may not be representative of the population.

\section{Conclusion}

The research is conducted to examine the relationship between SSCM practices and operational and environmental performance in organisations. A general framework is developed and an attempt is made to validate the framework using case studies. In particular, the study examined whether adoption of environmental practices in supply chain management results in a positive impact on environmental and operational performance of companies. The research is expected to provide guidance in regard to the implementation of environmental supply chain management practices and to increase their international competitiveness that will result in economic benefits. Significant concern is prevailing at present about reduction of greenhouse gas emissions and preservation of the natural environment for future generation. The study, whose whole purpose is the investigation of the environmental aspects of supply chain management will go a long way in addressing this concern.

\section{Acknowledgements}

The author wishes to acknowledge that an earlier version of the paper was published in the Proceedings of 1st International Conference on Logistics and Transport, Thailand in 2009.

\section{REFERENCES}

[1] J, Sarkis, “A Strategic Decision Framework for Green Supply Chain Management,” Journal of Cleaner Production, Vol. 11, No. 4, 2003, pp. 397-409.

[2] P. Rao, "Greening the Supply Chain: A New Initiative in South East Asia," International Journal of Operations and Production Management, Vol. 22, No. 6, 2002, pp. 632-655. doi:10.1108/01443570210427668

[3] J. Sarkis, "How Green Is the Supply Chain? Practice and Research,” Graduate School of Management, Clark University, Worchester, 1999.

[4] Q. Zhu and J. Sarkis, "Green Supply Chain Management in China: Pressures, Practices and Performance,” International Journal of Operations and Production Management, Vol. 25, No. 5, 2005, pp. 449-468. doi:10.1108/01443570510593148

[5] J. Hutchison, "Integrating Environmental Criteria into Purchasing Decision: Value Added? In: T. Russel, Ed., Green Purchasing: Opportunities and Innovations, Green- leaf Publishing, Sheffield, 2003, pp. 164-178.

[6] R. I. van Hock and Erasmus, "From Reversed Logistics to Green Supply Chains,” Logistics Solutions, No. 2, 2000, pp. 28-33.

[7] H. Min and W. P. Galle, "Green Purchasing Strategies: Trends and Implications," International Journal of Purchasing and Material Management, Vol. 33, No. 3, 1997, pp. 10-17.

[8] M. J. Birell, "Encouraging Green Procurement Practices in Business: A Canadian Case Study in Programme Development," In: T. Russel, Ed., Greener Purchasing: Opportunities and Innovations, Greenleaf Publishing, Sheffield, 1998, pp. 108-117.

[9] R. M. Monszka and R. J. Trent, "Purchasing and Sourcing Strategy: Trends and Implications,” Center for Advance Purchasing Studies, Tempe, 1995.

[10] K. Green, B. Morton and S. New, "Green Purchasing and Supply Policies: Do They Improve Companies’ Environmental Performance?” Supply Chain Management, Vol. 3, No. 2, 1998, pp. 89-95. doi:10.1108/13598549810215405

[11] N. Walley and B. Whitehead, "It Is Not Easy Being Green,” Harvard Business Review, Vol. 72, No. 3, 1994, pp. 46-51.

[12] R. D. Klassen and C. P. McLaughlin, "The Impact of Environment Management on Firm Performance,” Management Science, Vol. 42, No. 8, 1996, pp. 1199-1214. doi:10.1287/mnsc.42.8.1199

[13] F. M. Gallop and M. J. Roberts, "Environmental Regulation and Productivity Growth: The Case of Fossil-Fueled Electric Power Generation,” Journal of Political Economy, Vol. 91, No. 4, 1983, pp. 654-674.

[14] R. Florida, "Lean and Green: The Move to Environmentally Conscious Manufacturing,” California Management Review, Vol. 39, No. 1, 1996, pp. 80-105. doi: $10.2307 / 41165877$

[15] R. Handfield, S. V. Walton, R. Sroufe and S. A. Melnyk, "Applying Environmental Criteria to Supplier Assessment: A Study in the Application of Analytical Hierarchy Process," European Journal of Operational Research, Vol. 141, No. 1, 2002, pp. 70-87. doi:10.1016/S0377-2217(01)00261-2

[16] R. Florida and D. Davison, “Gaining from Green Management: Environmental Management Systems Inside and Outside the Factory," California Management Review, Vol. 43, No. 3, 2001, pp. 64-84. doi:10.2307/41166089

[17] B. Keating, A. Quazi, A. Kriz and T. Coltman, "In Persuit of a Sustainable Supply Chain: Insights Form Westpac Banking Corporation,” Supply Chain Management, Vol. 13, No. 3, pp. 175-179. doi:10.1108/13598540810871217

[18] R. Frosch, "Industrial Ecology: Minimising the Impact of Industrial Waste,” Physics Today, Vol. 47, No. 11, 1994, pp. 63-68. doi:10.1063/1.881405

[19] C. Geffen and S. Rothenberg, "Sustainable Development across Firm Boundaries: The Critical Role of Suppliers in Environmental Innovation,” International Journal of Operations and Production Management, Vol. 20, No. 2, 2000, pp. 166-186. 
[20] M. Wagner, S. Schaltegger and W. Wehrmeyer, "The Relationship between the Environmental and Economic Performance of Firms: What Does Theory Propose and What Does Empirical Evidence Tell Us," Greener Management International, No. 34, 2001, pp. 95-108.

[21] M. J. A. Gil, J. B. Jimenez and J. C. Lorenter, “An Analysis of Environmental Management, Organisational Context and Performance of Spanish Hotels,” Omega, Vol. 29, No. 6, 2001, pp. 457-471. doi:10.1016/S0305-0483(01)00033-0

[22] F. E. Bowen, P. D. Cousins, R. C. Lamming and A. C. Raruk, "Horse for Courses: Explaining the Gap between the Theory and Practice of Green Supply," Greener Management International, No. 35, 2001, pp. 41-60.

[23] T. B. Szwilski, "Using Environmental Management Systems to Systematically Improve Operational Performance and Environmental Protection," International Journal of Surface Mining, Reclamation and Environment, Vol. 14, No. 3, 2000, pp. 183-191. doi:10.1080/13895260008953322

[24] S. Tooru, "Certification and Operational Performance of ISO14001,” Kamipa Gikyoshi, Vol. 55, No. 1, 2001, pp. 52-58.

[25] M. D. Hanna, W. R. Newman and P. Johnson, "Linking Operational and Environmental Improvement through Employee Involvement," International Journal of Operations and Production Management, Vol. 20, No. 2, 2000, pp. 148-165. doi:10.1108/01443570010304233

[26] Q. Zhu and J. Sarkis, "The Moderating Effects of Institutional Pressure on Emergent Green Supply Chain Practices and Performance," International Journal of Production Research, Vol. 45, No. 18-19, pp. 4333-4355.

[27] R. B. Dean and R. L. Brown, "Pollution Regulation as a Barrier to New Firm Entry: Initial Evidence and Implications for Future Research,” Academy of Management Journal, Vol. 38, No. 1, 1995, pp. 288-303. doi:10.2307/256737

[28] M. E. Porter and C. van der Linde, "Green and Competitive: Ending the Stalemate," Harvard Business Review, Vol. 73, No. 5, 1995, pp. 120-134.

[29] M. Orlitzky, F. L. Schmidt and S. L. Rynes, "Corporate Social and Financial Performance: A Meta-Analysis," Organisation Studies, Vol. 24, No. 3, 2003, pp. 403-441. doi:10.1177/0170840603024003910

[30] G. A. Zsidisin and T. E. Hendrick, "Purchasing’s Involvement in Environmental Issues: A Multi-Country Perspective,” Industrial Management and Data Systems, Vol. 98, No. 7, 1998, pp. 1-73.

[31] S. V. Walton, R. B. Handfield and S. T. Melnyk, "The Green Supply Chain: Integrating Suppliers into Environmental Management Process," International Journal of Purchasing and Materials Management, Vol. 34, No. 2, 1998, pp. 2-11.

[32] G. A. Zsidisin and S. P. Siferd, "Environmental Purchasing: A Framework for Theory Development," European Journal of Purchasing and Supply Management, Vol. 7,
No. 1, 2001, pp. 1-73. doi:10.1016/S0969-7012(00)00007-1

[33] Q. Zhu and J. Sarkis, "Relationship between Operational Practices and Performance among Early Adopters of GSCM Practices in Chinese Manufacturing Enterprises," Journal of Operations Management, Vol. 22, No. 3, 2004, pp. 265-289. doi:10.1016/j.jom.2004.01.005

[34] C. R. Carter, L. M. Ellram and L. M. Kathryn, "Environmental Purchasing: Benchmarking Our German Counterparts,” International Journal of Purchasing and Materials Management, Vol. 34, No. 4, 1998, pp. 28-38.

[35] G. Hamel and C. K. Prahalad, "Strategic Intent,” Harvard Business Review, Vol. 67, No. 2, 1989, pp. 63-76.

[36] S. V. Walton, R. B. Handfield and S. T. Melnyk, "The Green Supply Chain: Integrating Suppliers into Environmental Management Process," International Journal of Purchasing and Materials Management, Vol. 34, No. 2, 1998, pp. 2-11.

[37] G. Noci, "Environmental Reporting on Italy: Current Practices and Future Developments,” Business Strategy and Environment, Vol. 9, No. 4, 2000, pp. 211-223. doi:10.1002/1099-0836(200007/08)9:4<211::AID-BSE24 8>3.0.CO;2-9

[38] P. Rao and D. Holt, "Do Green Supply Chains Lead to Competitiveness and Economic Performance," International Journal of Operations and Production Management, Vol. 25, No. 9, 2005, pp. 808-916. doi:10.1108/01443570510613956

[39] L. Kroon and G. Vrijens, "Returnable Containers: An Example of Reverse Logistics," International Journal of Physical Distribution and Logistics Management, Vol. 25, No. 2, 1995, pp. 56-68. doi:10.1108/09600039510083934

[40] A. Menon and A. Menon, "Environmental Marketing Strategy: The Emergence of Corporate Environmentalism as Marketing Strategy,” Journal of Marketing, Vol. 61, No. 1, 1997, pp. 51-67. doi:10.2307/1252189

[41] H. J. Wu and S. C. Dunn, "Environmentally Responsible Logistics Systems,” International Journal of Physical Distribution and Logistics Management, Vol. 25, No. 2, 1995, pp. 20-38. doi:10.1108/09600039510083925

[42] Eastman Chemical Company. www.eastman.com/company/sustainability/pages/supplychain1.aspx

[43] B. Keating, A. Quazi, A. Kriz and T. Coltman, "In Pursuit of a Sustainable Supply Chain: Insights from Westpac Banking Corporation,” Supply Chain Management: An International Journal, Vol. 13, No. 3, 2008, pp. 175-179.

[44] New Zealand Business Council for Sustainable Development, "Business Guide to a Sustainable Supply Chain: A Practical Guide,” 2003.

[45] Coca-Cola Enterprises, “Our CRS Journey Delivering on Our Commitments: Corporate Responsibility and Sustainability (CRS) Report,” 2008.

[46] Ermst and Young, "Green for Go: Supply Chain Sustainability," 2008. 